\title{
Optical biometry-based axial length alterations after intravitreal dexamethasone implant
}

\author{
Alterações do comprimento axial com base na biometria óptica após o \\ implante de dexametasona intravítrea
}

\author{
Sadık Altan Ozal', Ayca Kupelı', Ece Ozal², Vuslat Gurlu \\ 1. Trakya University School of Medicine, Department of Ophthalmology, Edirne, Turkey. \\ 2. Edirne State Hospital, Department of Ophthalmology, Edirne, Turkey.
}

\begin{abstract}
I Purpose: To investigate changes in axial length after intravitreal dexamethasone implantation in patients with macular edema. Methods: We performed a prospective comparative study of 46 patients with unilateral macular edema, due to diabetic retinopathy, retinal vein occlusion, and non-infectious uveitis, who underwent dexamethasone implantation. The fellow eyes of the patients were considered the control group. The central macular thickness was measured by spectral-domain optical coherence tomography, and axial length was measured by IOLMaster 700 optical coherence biometry. We compared axial length and central macular thickness values within the groups. Results: In the study group, the baseline central macular thickness was $460.19 \pm$ $128.64 \mu \mathrm{m}$, significantly decreasing to $324.00 \pm 79.84 \mu \mathrm{m}$ after dexamethasone implantation $(p=0.000)$. No significant change in central macular thickness measurements was seen in the control group $(p=0.244)$. In the study group, the baseline axial length was $23.16 \pm 0.68 \mathrm{~mm}$, significantly increasing to $23.22 \pm 0.65 \mathrm{~mm}$ after dexamethasone implantation $(p=0.039)$. However, the control group exhibited no significant change in axial length $(p=0.123)$. Conclusions: In addition to significantly reducing central macular thickness measurements, intravitreal dexamethasone implantation also significantly changes optical biometry-based axial length measurements.
\end{abstract}

Keywords: Axial length, eye; Dexamethasone/administration \& dosage; Intravitreal injections, Drug implants; Macular edema

\footnotetext{
Submitted for publication: September 13, 2018

Accepted for publication: October 19, 2018

Funding: No specific financial support was available for this study.

Disclosure of potential conflicts of interest: None of the authors have any potentia conflicts of interest to disclose.

Corresponding author: Sadık Altan Ozal

Trakya University, School of Medicine. Department of Ophthalmology - Edirne, Turkey - E-mail: altanozal@hotmail.com

Approved by the following research ethics committee: Trakya University Faculty of Medicine Scientific Research Ethics Committee (\# TUTF-BAEK 2017/333).
}

RESUMO | Objetivo: Investigar alterações no comprimento axial após implante de dexametasona intravítrea em pacientes com edema macular. Métodos: Foi realizado um estudo prospectivo e comparativo de 46 pacientes com edema macular unilateral, devido à retinopatia diabética, oclusão da veia retiniana e uveíte não infecciosa, que foram submetidos ao implante de dexametasona. Os olhos contralateral de cada paciente foram considerados o grupo controle. A espessura macular central foi medida por tomografia de coerência óptica de domínio espectral, e o comprimento axial foi medido por meio de biometria de coerência óptica de domínio espectral e o comprimento axial foi medido pela biometria de coerência óptica com IOLMaster 700. Comparamos o comprimento axial e os valores da espessura macular central dentro dos grupos. Resultados: No grupo de estudo, a espessura macular basal foi de 460,19 $\pm 128,64 \mu \mathrm{m}$, diminuindo significativamente para 324,00 $\pm 79,84 \mu \mathrm{m}$ após o implante de dexametasona $(p=0,000)$. Nenhuma mudança significativa nas medidas da espessura macular central foi observada no grupo controle $(p=0,244)$. No grupo de estudo, o comprimento axial basal foi de $23,16 \pm 0,68 \mathrm{~mm}$, aumentando significativamente para 23,22 $\pm 0,65 \mathrm{~mm}$ após o implante de dexametasona $(p=0,039)$. No entanto, o grupo controle não apresentou alteração significativa no comprimento axial $(p=0,123)$. Conclusões: Além de reduzir significativamente as medidas da espessura macular central, o implante de dexametasona intravítrea também altera significativamente as medidas de comprimento axial baseadas na biometria óptica.

Descritores: Comprimento axial do olho; Dexametasona/ administração \& dosagem; Injeções intravítreas; Implantes de medicamento; Edema macular

\section{INTRODUCTION}

Dexamethasone (DEX) is a potent, water-soluble corticosteroid. The Ozurdex DEX implant $0.7 \mathrm{mg}$ (Allergan Pharmaceuticals, Irvine, CA, USA) is an injector system containing lactic acid, glycolic acid, and DEX, allowing 
for a slow release of the drug and can be injected into the vitreous cavity via the pars plana ${ }^{(1)}$. A DEX implant is approved by the Food and Drug Administration for the treatment of diabetic macular edema ${ }^{(2)}$, macular edema due to retinal vein occlusions ${ }^{(3)}$, and non-infectious uveitis $^{(4)}$. Furthermore, a DEX implant is used commonly to treat age-related macular degeneration, retinitis pigmentosa, Irvine-Gass syndrome, retinal telangiectasia, and macular edema following pars plana vitrectomy ${ }^{(5-10)}$. Cataract development is the most important factor reducing visual gain that can occur after DEX implantation in phakic patients. The rate of cataract development is reportedly between $22.2 \%^{(11)}$ and $67.9 \%^{(2)}$ after DEX implantation in phakic patients. Cataract surgery is frequently performed postoperatively in patients treated with DEX implantation due to cataract progression.

Measuring the axial length (AL) prior to cataract surgery is the most important procedure to ensure correct intraocular lens placement, and emmetropia can be achieved postoperatively. The AL is measured via ultrasound and optical biometry methods ${ }^{(12)}$. The non-contact nature of optical biometrics has several advantages over ultrasound biometrics, including more accurate and reproducible measurements ${ }^{(13,14)}$. While ultrasound biometry measures the distance between the corneal vertex and the internal limiting membrane, optical coherence biometry measures the distance between the corneal vertex and the retinal pigment epithelium (RPE). The effect of DEX implantation on macular edema is quantitatively analyzed by measuring the central macular thickness (CMT) using spectral-domain optical coherence tomography (OCT). Patients responding well to DEX implantation experience decreases in macular edema and CMT and an increase in best-corrected visual acuity $(\mathrm{BCVA})^{(15,16)}$. An accurate $\mathrm{AL}$ measurement in these patients is required before cataract surgery due to the frequent development of cataract in the following period.

This study aimed to investigate whether changes in the CMT after DEX implantation produced a change in the AL.

\section{METHODS}

We conducted a prospective controlled, comparative study in patients who underwent DEX implantation between January 2018 and March 2018 in the retina unit of our clinic. The study included patients who underwent DEX implantation with unilateral macular edema due to diabetic retinopathy, retinal vein occlusion, and non-infectious uveitis. The fellow eyes of patients were considered the control group. Patients with dense cataract preventing optical biometry and OCT measurements, corneal opacification, previous intravitreal injection, RPE detachment, previous eye surgery, glaucoma, high hypermetropia, and high myopia were excluded. All patients were informed about the treatment and the potential complications. Informed consent was obtained from all patients preoperatively. The study procedures were approved by the hospital's institutional review board and were in accordance with the principles of the Declaration of Helsinki. The study protocol was approved by the local ethics committee (approval code: TUTF-BAEK 2017/333).

The same experienced ophthalmologist (AK) performed detailed ophthalmologic examinations of the patients before and after DEX implantation. BCVA was measured with the Early Treatment Diabetic Retinopathy Study chart. A biomicroscopic slit-lamp examination was performed, and the intraocular pressure (IOP) was measured by a Goldmann applanation tonometer (AT 900, Haag-Streit Diagnostics, Koeniz, Switzerland). A detailed fundus examination was performed using a 78 diopter non-contact lens (Volk Optical Inc., Mentor, OH, USA). All patients were assessed for CMT values using spectraldomain OCT (RS-3000 Lite, Nidek, Japan). Intraretinal and/or subretinal fluid found on OCT (CMT $\geq 250 \mu \mathrm{m})$ was considered macular edema. AL measurements were performed using swept-source OCT-based optical biometry (IOLMaster 700, Carl Zeiss Meditec AG, Jena, Germany). Fundus fluorescein angiography (TRC-50IX Retinal Camera, Topcon Corporation, Tokyo, Japan) was performed in all patients before DEX implantation, and late hyperfluorescence in the perifoveal area was considered macular edema. All patients were recalled at the second month after intravitreal DEX implantation and the measurements were repeated. Topical antiglaucomatous medication was initiated as needed according to postoperative IOP levels. AL and CMT values were compared within the groups.

\section{Intravitreal DEX implantation}

All intravitreal DEX implantations were performed by the same surgeon (AO) under sterile conditions. Topical anesthesia was administered using 5\% propacaine hydrochloride (Alcaine, Alcon Laboratories, Inc., Ft. Worth, TX, USA). Antiseptic $10 \%$ povidone iodine was used to irrigate the eyelashes, eyelids, and periorbicular tissues. After inserting an eye speculum, $5 \%$ povidone iodine was flushed onto the conjunctiva and fornix for 2 
minutes, and conjunctival irrigation was completed with saline. Intravitreal DEX implantation was performed in 2 steps at the inferotemporal quadrant and $4 \mathrm{~mm}$ posterior to the limbus. After DEX implantation, the scleral entry was replaced by a cotton-tipped applicator. Postoperatively, patients received $0.5 \%$ topical moxifloxacin (Vigamox, Alcon) 4 times daily for 1 week.

\section{Statistical analysis}

A total of 46 participants were included in the study as a result of power analysis performed at $80 \%$ power and $5 \%$ significance level. IBM SPSS Statistics for Windows, version 20.0 (IBM Corp., Armonk, NY, USA), was used for statistical analysis. Prior to performing calculations on the non-qualitative data, the Kolmogorov-Smirnov test was used to determine conformity of the data with normal distribution. Parametric variables were evaluated using the paired $t$-test, and non-parametric variables were assessed using the Wilcoxon signed-rank test. A $p$ value $<0.05$ was considered statistically significant.

\section{RESULTS}

A total of 92 eyes (46 study eyes, 46 controls) of 46 patients were included in the present study. Table 1 shows the baseline patient demographics, and table 2 shows the baseline and follow-up measurements for the study and control groups. In the study group, the baseline CMT was $460.19 \pm 128.64 \mu \mathrm{m}$, significantly decreasing to $324.00 \pm 79.84 \mu \mathrm{m}$ after DEX implantation $(p=0.000)$. No significant change in CMT measurements was exhibited in the control group $(p=0.244)$. In the study group, the baseline AL was $23.16 \pm 0.68 \mathrm{~mm}$, significantly increasing to $23.22 \pm 0.65 \mathrm{~mm}$ after DEX implantation $(p=0.039)$. However, no significant change in AL levels was seen in the control group $(p=0.123)$.

\section{DISCUSSION}

The most important parameter is an accurate AL measurement in the preoperative period in order to obtain good refractive results after cataract surgery ${ }^{(17,18)}$. The AL can be measured with ultrasound biometry or more popular optical biometry devices. Optical biometry is superior in many ways to ultrasound biometry in measuring the $\mathrm{AL}$, including the non-contact feature and fast, accurate, and reproducible measurements. Hitzenberger et al. ${ }^{(19)}$ reported that the AL measured with optical biometry was $0.18 \mathrm{~mm}$ longer than that measured by the immersion technique and $0.47 \mathrm{~mm}$ longer than that
Table 1. Numeric and percentage views of baseline patient demographics

\begin{tabular}{lc}
\hline Parameter & Value \\
\hline Age (years) & $65.6 \pm 9.6$ \\
Mean \pm SD & $28-88$ \\
Range & \\
Sex, n (\%) & $25(54.3)$ \\
Men & $21(45.7)$ \\
Women & \\
Cause of macular edema, n (\%) & $34(73.9)$ \\
DME & $6(13.0)$ \\
RVO & $6(13.0)$ \\
Uveitis &
\end{tabular}

Table 2. Comparisons of axial length and central macular thickness alterations within the study and control groups

\begin{tabular}{lcc}
\hline Parameter & Study group & Control group \\
\hline CMT1 $(\mu \mathrm{m})$ & $460.19 \pm 128.64$ & $303.65 \pm 74.09$ \\
CMT2 $(\mu \mathrm{m})$ & $324.00 \pm 79.84$ & $293.86 \pm 42.19$ \\
p-value & 0.000 & 0.244 \\
AL1 $(\mathbf{m m})$ & $23.16 \pm 0.68$ & $23.13 \pm 0.62$ \\
AL2 $(\mathbf{m m})$ & $23.22 \pm 0.65$ & $23.12 \pm 0.64$ \\
p-value & $\mathbf{0 . 0 3 9}$ & 0.123 \\
\hline
\end{tabular}

CMT1 = baseline central macular thickness; $\mathrm{CMT} 2$ = follow-up central macular thickness; $\mathrm{AL} 1=$ baseline axial length; $\mathrm{AL} 2=$ follow-up axial length .

using the applanation technique, possibly because the applanation of the probe is pressed on the cornea, and the $\mathrm{AL}$ is measured shorter in ultrasound biometry. Kiss et al. ${ }^{(19)}$ reported that ultrasound biometry by the immersion technique has results similar to optical biometry in terms of postoperative refractive results. However, many other studies have reported better refractive results with optical biometry compared to ultrasound biometry in the postoperative period ${ }^{(13,20)}$.

Lam et al. ${ }^{(21)}$ reported that there was no significant difference in AL measurements made by optical biometry between different practitioners, indicating that reproducibility was high. Another reason that $\mathrm{AL}$ measurements with optical biometry are more accurate than those with ultrasound biometry is the use of a long, low-resolution wavelength in ultrasound biometry. Ultrasound biometry measures the distance between the corneal vertex and the internal limiting membrane, while optical biometry measures the distance between the corneal vertex and the RPE. The distance measured by ultrasound biometry is shorter than that by optical biometry. Thus, it has been 
suggested that retinal thickening in the foveal region affects ultrasound biometry measurements, but not optical biometry measurements ${ }^{(12)}$. The lOLMaster 500 device measures the AL by passing the 780-nm infrared laser beam through the visual axis. Patients' eyes should be fixed on the laser beam during this measurement. Many studies ${ }^{(22,23)}$ have reported that $8-20 \%$ of patients' eyes could not be measured with the lOLMaster 500 due to poor fixation, corneal opacities, advanced cataracts, and the presence of dense media opacities. The lOLMaster 700 is a new swept-source OCT that can measure the $\mathrm{AL}$ even in the presence of media opacities due to its high tissue permeability and better signal-to-noise ratio. In the present study, AL measurements were obtained using the lOLMaster 700 device ${ }^{(14,24)}$.

Optical biometric measurements are reportedly affected by pharmacological mydriasis ${ }^{(25)}$; thus, we performed all biometric measurements in our study before mydriasis. We repeated all the measurements in the second postoperative month in which macular edema was most markedly reduced. In the literature, only 1 study investigated whether intravitreal injections had an effect on AL measurements ${ }^{(26)}$. Kymionis et al. ${ }^{(26)}$ reported a significant decrease in CMT levels, but no significant change in AL levels 2 months after intravitreal ranibizumab administration when compared to the preoperative level. In the present study, we observed a significant decrease in CMT levels and a significant increase in $\mathrm{AL}$ levels in the study group at the second postoperative month. There was no change in CMT and AL levels in the control group. We think that the increase in $\mathrm{AL}$ levels in our study group may be due to the healing effect of the DEX implant on RPE. It has been reported previously that the DEX implant has a restoring effect on the outer retinal layers, RPE, and normal RPE reflectivity $^{(27,28)}$. The DEX implant reduces inflammatory cytokines, leading to stabilization of the RPE tight junctions. Although none of the patients in the present study had RPE detachments, the stabilization of RPE tight junctions may alter the distance from the corneal vertex to the RPE.

A $1 \mathrm{~mm}$ error in AL measurement leads to 3 diopter refractive changes after cataract surgery ${ }^{(29)}$. In our study, the baseline mean $\mathrm{AL}$ values were $23.16 \pm 0.68 \mathrm{~mm}$ and $23.22 \pm 0.65 \mathrm{~mm}$ at the second postoperative month. Despite a statistically significant difference, a change in $\mathrm{AL}$ values at this level may not clinically affect the ability to obtain good refractive results after cataract surgery. The fact that the number of cases in our study is larger than that in a similar study in the literature in addition to having a control group are powerful features of our study. Since most of the patients included in our study had diabetic macular edema, the number of patients with macular edema due to uveitis and retinal vein occlusion was very small. Therefore, we could not perform subgroup analysis. Moreover, our comparisons were limited by the short follow-up time.

Cataract progression often occurs after DEX implantation, and these patients are required to have cataract surgery in the future. The visual gain obtained by the reduction of macular edema after DEX implantation may be somewhat overshadowed by the development of cataract. The most important criterion to achieve emmetropia after cataract surgery is an accurate preoperative measurement of the AL. In conclusion, we demonstrated a statistically significant increase in AL values after intravitreal DEX implantation. This is the first published study to investigate the effect of intravitreal DEX implantation on AL measurements. However, studies with longer optical follow-up times and those comparing different optical biometry devices in larger subject groups are needed in order to better illuminate this topic.

\section{REFERENCES}

1. Haller JA, Kuppermann BD, Blumenkranz MS, Williams GA, Weinberg DV, Chou C, et al., Dexamethasone DDS Phase Il Study Group. Randomized controlled trial of an intravitreous dexamethasone drug delivery system in patients with diabetic macular edema. Arch Ophthalmol. 2010;128(3):289-96.

2. Boyer DS, Yoon YH, Belfort R Jr, Bandello F, Maturi RK, Augustin AJ, et al.; Ozurdex MEAD Study Group. Three-year, randomized, sham-controlled trial of dexamethasone intravitreal implant in patients with diabetic macular edema. Ophthalmology. 2014;121(10):1904-14.

3. Haller JA, Bandello F, Belfort R Jr, Blumenkranz MS, Gillies M, Heier J, et al.; OZURDEX GENEVA Study Group. Randomized, sham-controlled trial of dexamethasone intravitreal implant in patients with macular edema due to retinal vein occlusion. Ophthalmology. 2010;117(6):1134-1146.e3.

4. Lowder C, Belfort R Jr, Lightman S, Foster CS, Robinson MR, Schiffman RM, et al.; Ozurdex HURON Study Group. Dexamethasone intravitreal implant for noninfectious intermediate or posterior uveitis. Arch Ophthalmol. 2011;129(5):545-53.

5. Kuppermann BD, Goldstein M, Maturi RK, Pollack A, Singer M, Tufail A, et al.; Ozurdex ${ }^{\circledR}$ ERIE Study Group. Dexamethasone intravitreal implant as adjunctive therapy to ranibizumab in neovascular age-related macular degeneration: a multicenter randomized controlled trial. Ophthalmologica. 2015;234(1):40-54.

6. Dutra Medeiros M, Navarro R, Garcia-Arumí J, Mateo C, Corcóstegui $B$. Dexamethasone intravitreal implant for treatment of patients with recalcitrant macular edema resulting from Irvine-Gass syndrome. Invest Ophthalmol Vis Sci. 2013;54(5):3320-4.

7. Saatci AO, Selver OB, Seymenoglu G, Yaman A. Bilateral intravitreal dexamethasone implant for retinitis pigmentosa-related macular edema. Case Rep Ophthalmol. 2013;4(1):53-8. 
8. Merkoudis N, Granstam E. Treatment of postoperative cystoid macular oedema with dexamethasone intravitreal implant in a vitrectomized eye- a case report. Acta Ophthalmol. 2013;91(3): e238-9.

9. Bonfiglio V, Reibaldi M, Fallico M, Russo A, Pizzo A, Fichera S, et al. Widening use of dexamethasone implant for the treatment of macular edema. Drug Des Devel Ther. 2017;11:2359-72.

10. Abadia B, Calvo P, Ferreras A, Bartol F, Verdes G, Pablo L. Clinical Applications of Dexamethasone for Aged Eyes. Drugs Aging. 2016; 33(9):639-46.

11. Callanan DG, Gupta S, Boyer DS, Ciulla TA, Singer MA, Kuppermann BD, et al.; Ozurdex PLACID Study Group. Dexamethasone intravitreal implant in combination with laser photocoagulation for the treatment of diffuse diabetic macular edema. Ophthalmology. 2013;120(9):1843-51.

12. Lee AC, Qazi MA, Pepose JS. Biometry and intraocular lens power calculation. Curr Opin Ophthalmol. 2008;19(1):13-7.

13. Olsen T. Improved accuracy of intraocular lens power calculation with the Zeiss IOLMaster. Acta Ophthalmol Scand. 2007;85(1):84-7.

14. Shajari M, Cremonese C, Petermann K, Singh P, Müller M, Kohnen T. Comparison of axial length, corneal curvature, and anterior chamber depth measurements of 2 recently introduced devices to a known biometer. Am J Ophthalmol. 2017;178:58-64.

15. Veritti D, Sarao V, Galiazzo F, Lanzetta P. Early effects of dexamethasone implant on macular morphology and visual function in patients with diabetic macular edema. Ophthalmologica. 2017; 238(1-2):100-5.

16. Khan Z, Kuriakose RK, Khan M, Chin EK, Almeida DR. Efficacy of the intravitreal sustained-release dexamethasone implant for diabetic macular edema refractory to anti-vascular endothelial growth factor therapy: meta-analysis and clinical implications. Ophthalmic Surg Lasers Imaging Retina. 2017;48(2):160-6.

17. Holladay JT, Prager TC, Ruiz RS, Lewis JW, Rosenthal H. Improving the predictability of intraocular lens power calculations. Arch Ophthalmol. 1986;104(4):539-41.

18. Olsen T. Sources of error in intraocular lens power calculation. J Cataract Refract Surg. 1992;18(2):125-9.

19. Hitzenberger CK, Drexler W, Dolezal C, Skorpik F, Juchem M, Fercher AF, et al. Measurement of the axial length of cataract eyes by laser Doppler interferometry. Invest Ophthalmol Vis Sci. 1993; 34(6):1886-93.

20. Rose LT, Moshegov CN. Comparison of the Zeiss IOLMaster and applanation A-scan ultrasound: biometry for intraocular lens calculation. Clin Exp Ophthalmol. 2003;31(2):121-4.

21. Lam AK, Chan R, Pang PC. The repeatability and accuracy of axial length and anterior chamber depth measurements from the IOLMaster. Ophthalmic Physiol Opt. 2001;21(6):477-83.

22. Prinz A, Neumayer T, Buehl W, Kiss B, Sacu S, Drexler W, et al. Influence of severity of nuclear cataract on optical biometry. J Cataract Refract Surg. 2006;32(7):1161-5.

23. Freeman G, Pesudovs K. The impact of cataract severity on measurement acquisition with the IOLMaster. Acta Ophthalmol Scand. 2005;83(4):439-42.

24. Srivannaboon S, Chirapapaisan C, Chonpimai P, Loket S. Clinical comparison of a new swept-source optical coherence tomography-based optical biometer and a time-domain optical coherence tomography-based optical biometer. J Cataract Refract Surg. 2015;41(10):2224-32.

25. 25. Rodriguez-Raton A, Jimenez-Alvarez M, Arteche-Limousin L, Mediavilla-Peña E, Larrucea-Martinez l. Effect of pupil dilation on biometry measurements with partial coherence interferometry and its effect on $\mathrm{OOL}$ power formula calculation. Eur J Ophthalmol. $2015 ; 25(4): 309-14$.

26. Kymionis GD, Giarmoukakis A, Apostolidi IK, Blazaki SV, Tsoulnaras $\mathrm{Kl}$, Moschandrea J, et al. Optical biometry derived axial length measurements following intravitreal anti-vascular endothelial growth factor treatment for macular edema. Semin Ophthalmol. 2018;33(4):488-91.

27. Battaglia Parodi M, lacono P, Scaramuzzi M, Bandello F. Outer retinal layer changes after dexamethasone implant for central retinal vein occlusion. Retina. 2017;37(10):1888-95.

28. lacono P, Parodi MB, Scaramuzzi M, Bandello F. Morphological and functional changes in recalcitrant diabetic macular oedema after intravitreal dexamethasone implant. $\mathrm{Br} J$ Ophthalmol. 2017;101(6):791-5.

29. Zaldivar R, Shultz MC, Davidorf JM, Holladay JT. Intraocular lens power calculations in patients with extreme myopia. J Cataract Refract Surg. 2000;26(5):668-74. 